\title{
A study of the measurement of changes occurring in long-term psychiatric patients discharged to residential care in the community
}

\author{
Adrian E. G. Skinner, Principal Clinical Psychologist; and Christine M. Williams, \\ Assistant Psychologist, Department of Clinical Psychology and Department of \\ Psychiatry, Harrogate Health Authority, Norman House, 46 East Parade, \\ Harrogate HG1 5LT
}

As more health authorities close large psychiatric hospitals the provision of small local facilities in which former residents of such hospitals are housed is increasing. Such houses tend to share many common characteristics dictated both by practical necessity and by deliberate policy - they tend to be large Victorian houses chosen because they have a larger number of bedrooms and they tend to be run in a much less formal manner than hospital wards (Goldberg, 1985).

Research shows that there is an overall tendency for the quality of life (as measured by the QOL interview of Lehman (1983)), to be better in group homes as opposed to hospital wards (Simpson et al, 1989), but there is little published research which shows the effects that these changes have on patients' rehabilitation status after discharge into the community.

\section{The study}

The purpose of this study was to assess changes in patients' rehabilitation status, firstly after an initial rehabilitation programme and then after a seven month stay in Abdale House, a residential home in the community which was established in 1989. These patients were all formerly resident in the long-stay facility of Clifton Hospital, a large psychiatric hospital serving the county of North Yorkshire which is due to close and be replaced by smaller local facilities. Before moving to Abdale House, the 12 patients went through a basic two week rehabilitation programme designed to enhance their self-care skills.

The hostel was envisaged as a 'half way house', whose main aim was the rehabilitation and gradual discharge of patients into the community. However, it was not possible to select those best suited to this as some of the patients who had expressed a desire to return to the Harrogate area were felt unlikely to reach a sufficient standard of self-care, etc. to envisage a completely independent existence. However, the staff at Abdale House began to implement a programme which involves all the patients in the daily running of the house, including cleaning, washing, cooking, shopping and dishwasher rotas. The residents are encouraged to organise their own finances where appropriate. In addition, daily events are organised including various group activities aimed at aiding communication and socialisation skills. In many ways the methods used are similar to those reported by Goldberg et al (1985), but are less overtly behavioural in nature. There are, however, feedback meetings although the financial reinforcement element is absent.

As part of the process of assessing the success of the venture, it was felt important that the progress of the residents be monitored in an objective way independent of the halo effect that was naturally liable to surround this new venture undertaken by a young and enthusiastic staff group. It was also felt that assessment would help to provide objective indications of change in individual rehabilitation status and thereby enable the design of future programmes.

After reviewing the various methods of undertaking this task, we selected the Morningside Rehabilitation Status Scale-MRSS (Affleck \& McGuire, 1984) which is designed specifically to assess the progress and potential of long-stay psychiatric patients. The MRSS covers the four main areas of change which Affleck \& McGuire felt to be relevant to the rehabilitation of this group of patients: dependence, activity, social integration, and the effects of current symptoms. These are represented by the four subscales: dependency, inactivity, isolation, and effects of current symptoms.

The patients were assessed on three separate occasions: August 1988, in Clifton Hospital before any changes took place; February 1989 after a short rehabilitation programme on a ward; and October 1989 after eight months in Abdale House.

\section{Findings}

Our results demonstrated that the residents of Abdale House have improved as measured by the 
MRSS since their move to this facility. Overall eight patients showed this improvement and one regressed. When the patients were originally assessed in Clifton Hospital the mean level of dysfunction was $81.14 \%$. After seven months at Abdale House, this was reduced to a $66.94 \%$ dysfunction level, representing a total improvement of over $14 \%$. How is this reflected in the everyday life of a resident?

$\mathrm{He} / \mathrm{she}$ is likely to prepare, or share in preparing meals and take part in cleaning the house and other domestic activities. Outside activities have also increased - the residents garden, shop, go to local pubs and on organised outings. In most cases these activities were initiated by staff but are maintained by the whole community.

The most significant levels of improvement were on the dependency scale $(P<0.001)$. The original scores on this scale were at the maximum of 7 as the subjects were all looked after full-time on a hospital ward, and the scores tended to improve partially as a result of the increased opportunity for more independence. However, even after taking this into account there was still a significant improvement in a number of patients on this scale.

The inactivity subscale scores also show a substantial and significant improvement $(P<0.01)$ in the patients' ability to initiate and sustain purposeful activity since their transfer to Abdale House. They have shown an increasing tendency to plan and state preferences for activities, and to get a greater variety of activities into each day. It was felt that this was largely because patients are encouraged to take responsibility for themselves and their lifestyle.

The isolation scale is a measure of social competence. This scale showed the smallest amount of change in mean scores. This was partly because most of the residents scored relatively well on this scale on their initial assessment-and that willingness to interact and be 'part of the community' was a factor in selecting them for admission to Abdale House. However, although the improvement was small, it represented significant differences for some patients. Five patients in all showed improvement in this scale, four remained the same and two became worse.

Although there was no statistically significant difference in the Effects of Current Symptoms subscale, again the trend was towards improvement. Six patients improved, four remained the same and one deteriorated. This scale measures the extent to which the impairments effect the individual's lifestyle and that of those around him. The initial assessment in August 1988 revealed that nine of the 11 patients were considered to have "severe symptoms" (grades 5-7). This illustrates the extent of the pathology of the individuals involved. It is therefore particularly significant that their stay at Abdale House has resulted in overall improvement.
Total scores of the MRSS can be used to express the level of functioning in rehabilitation, e.g. 0-8 can represent high level functioning, 9-16, moderate level, 17-28, low level. The authors of the MRSS feel that survival in the community becomes very difficult for those scoring over 16 and almost impossible for those scoring over 20. In August 1988, ten of the 11 scored over 16, the eleventh scoring 16 , and nine scored over 20. In October 1989, seven scored over 16 , five scoring over 20 . Thus five individuals were now in the moderate level of functioning (9-16) and could be viewed as having potential for moving to less supervised accommodation.

The patients were then divided into two groups retrospectively: those who had progressed into the moderate level of functioning by October 1989 and those who remained in the low level. The data were analysed in this way in order to detect areas in which original differences in scores may help to determine eventual rehabilitation outcome. On the whole, those who started out with a greater degree of disability showed the least overall improvement. Those in the lower group had higher scores (i.e. a lower level of functioning), with an overall mean of four grades more than those in the moderate group.

It is also evident that the greatest difference originally was in the Effects of Current Symptoms scale by almost two grades. Both groups, however, showed a similar level of improvement $(0.7)$, on this scale, but the 'low' group improved much less on the other scales.

On the isolation scale, those in the low level of functioning group showed little or no improvement $($ mean $=0)$, whereas those in the moderate group showed a mean improvement of 1.4. There is a positive correlation between the Effsym score and the Isol score $(r=0.7)$, although it seems that improvement on the isolation scale may be dependent on the effects of current symptoms reaching a critical level. Similarly, those in the low level group failed to show the same levels of improvement on the inactivity scale as those in the moderate group. The implication is therefore that the extent of impairment as measured by the Effsym scale is of particular significance to rehabilitation status. If the individual's current symptoms are severe, improvement on the remaining scales is likely to be small and particularly so on the isolation scale. The implications for selection of patients for residence in facilities such as Abdale House is clear - those who currently or repeatedly show a high level of symptomatology are likely to do less well, whatever their levels of dependence, isolation or activity.

In conclusion, we feel that the results here are encouraging. Placing correctly selected long-term psychiatric patients in facilities such as Abdale House results in those people improving symptomatically, being more active, less dependent and 
isolated and, we hope, happier. The results indicate an overall improvement in functioning throughout the subscales and undoubtedly represent a substantial increase in the quality of life of the residents. There is also a general feeling from all of the staff involved in the use of the MRSS that the scale is a quick and useful measure of rehabilitation status. Further, it has been found that the individual profiles which are produced as a result of assessment provide a useful indication of progress/deterioration in each of the scales which may then be used in the design of future programmes. It is intended that the MRSS be used as part of a six monthly assessment programme in the future.

\section{References}

AfFleck, Jamies W. \& McGuirre, Ralph J. (1984) The measurement of psychiatric rehabilitation status. A review of the needs and a new scale. British Journal of Psychiatry, 145, 517-525.

GolDBERG, D. P. et al (1985) Douglas House: a new type of hostel ward for chronic psychotic patients. British Journal of Psychiatry, 147, 383-388.

Lehman, A. F. (1983) The well being of chronic mental patients. Assessing their quality of life. Archives of General Psychiatry, 40, 369-373.

Simpson, C. J., HyDE, C. E. \& FARAGHER, E. B. (1989) The chronically mentally ill in community facilities. A study of quality of life. British Journal of Psychiatry, 154, 77-82.

\section{ANNIVERSARY BALL}

As part of the celebrations to commemorate the 150th Anniversary of its origins

The Royal College of Psychiatrists is holding an

ANNIVERSARY BALL THE NATURAL HISTORY MUSEUM SOUTH KENSINGTON, LONDON

Tuesday 22 October 1991 7.00 for 7.30

Come and dance round the dinosaur to the music of THE DARK BLUES

The price of your ticket also includes aperitifs, a splendid dinner and wine

Tickets

There is a reduced price for tickets booked before 1 September:

Tickets purchased before 1 September: $£ 70$

Tickets purchased after 1 September: $£ 75$

Tables of eight purchased before 1 September: $£ 520$

Tables of eight purchased after 1 September: $\mathbf{\$ 5 6 0}$

Please apply to Christine Gear for application forms 071-235 2351, Ext. 131 